\title{
N-Acetyltransferase 2 (NAT2) Acetylator Status among Systemic Lupus Erythematosus Patients from A Tuberculosis Endemic Area in Bandung, Indonesia
}

\author{
Laniyati Hamijoyo ${ }^{1,2}$, Sasfia Candrianita ${ }^{2}$, Ika Agus Rini ${ }^{3}$, Endang Sutedja ${ }^{4}$, Budi Setiabudiawan ${ }^{5}$, \\ Edhyana Sahiratmadja ${ }^{3,6, *}$ \\ ${ }^{1}$ Rheumatology Division, Department of Internal Medicine, Faculty of Medicine, Universitas Padjadjaran/ Dr. Hasan Sadikin General Hospital, \\ Jl. Pasteur 38, Bandung, Indonesia \\ ${ }^{2}$ Lupus Study Group, Immunology Study Center, Faculty of Medicine, Universitas Padjadjaran, Jl. Eyckman 38, Bandung, Indonesia \\ ${ }^{3}$ Research Center of Medical Genetic, Faculty of Medicine, Universitas Padjadjaran, Jl. Eyckman 38, Bandung, Indonesia \\ ${ }^{4}$ Division of Immunology, Department of Dermatology, Faculty of Medicine, Universitas Padjadjaran/Dr. Hasan Sadikin General Hospital, \\ Jl. Pasteur 38, Bandung, Indonesia \\ ${ }^{5}$ Division of Immunology, Department of Pediatry, Faculty of Medicine, Universitas Padjadjaran/Dr. Hasan Sadikin General Hospital, \\ Jl. Pasteur 38, Bandung, Indonesia \\ ${ }^{6}$ Division of Biochemistry and Molecular Biology, Department of Biomedical Sciences, Faculty of Medicine, Universitas Padjadjaran, \\ Jl. Raya Sumedang Km 21, Indonesia \\ *Corresponding author. E-mail: e.sahiratmadja@unpad.ac.id
}

Received date: Sep 19, 2018; Revised date: Feb 1, 2019; Accepted date: Feb 6, 2019

\section{Abstract}

$\mathrm{B}$ ACKGROUND: Systemic lupus erythematosus (SLE) patients living in Indonesia are prone to tuberculosis (TB) infection, since this country ranks second globally for $\mathrm{TB}$ prevalence. Isoniazid, an anti-tuberculosis (TB) drug, is metabolized by enzyme $\mathrm{N}$-acetyltransferase 2 (NAT2) that is encoded by NAT2 gene. NAT2 haplotype, referring as acetylator status, may predispose as genetic factor in SLE development or complicate SLE therapy. This study explored the NAT2 haplotypes and acetylator status among SLE patients living in a TB endemic area.

METHODS: Genomic DNA of 260 registered SLE patients at The Rheumatology Clinic of Dr. Hasan Sadikin General Hospital, Bandung, Indonesia were isolated. NAT2 gene was amplified and sequenced, then NAT2 haplotypes and the acetylator status among SLE patients with or without TB history were determined and presented.
RESULTS: Most of SLE patients registered were female $(\mathrm{n}=250 ; 96.2 \%)$. The median age of patients when SLE was diagnosed for the first time was 27 years old (8-69 years), with organ involvement predominantly in musculoskeletal (80.8\%) and mucocutaneous (73.1\%). TB history, mostly pulmonary $\mathrm{TB}$, was present in $23.1 \%$ of SLE patients of whom TB was diagnosed before SLE (10.4\%) or after SLE $(10.7 \%)$ or both before and after SLE (2\%). The acetylator status was mostly intermediate $(61.5 \%)$ with the NAT2*4/*6 was the most prevalent haplotype (25.8\%).

CONCLUSION: There is a high number of intermediate and low acetylator status among SLE patients. Since these SLE patients live in TB endemic area, the NAT2 acetylator status determination among SLE patients before starting TB therapy may have clinical benefit to decrease a possible drug induced liver injury, and this warrants further study.

KEYWORDS: NAT2, acetylator, systemic lupus erythematosus, tuberculosis

Indones Biomed J. 2019; 11(2): 175-81 


\section{Introduction}

Systemic lupus erythematosus (SLE) is a complex chronic condition due to abnormality of immune system. The etiology of SLE is still unknown, as the SLE immune system has lost their self-tolerance resulting in an immune dysregulation.(1) Recently, genetic involvement in SLE is becoming central, triggered by environmental i.e., UV exposure, smoking and other stochastic factors such as hormonal factor, some infections and many other factors contributing to the development of disease.(2) Genome wide association studies have shown evidence and propose some candidate regions towards susceptibility to SLE from variation in many genes, especially in the host immune system. Certain genes involved in the pathway of toll like receptors (TLR) and type 1 interferon, immune signal transduction, immune complex processing may play roles in the SLE susceptibility.(3) Interestingly, genes i.e., signal transducer and activator of transcription 4 (STAT4), protein tyrosine phosphatase non-receptor type 22 (PTPN22), Tumor necrosis factor, alpha-induced protein 3 (TNFAIP3), and many other genes that are expressed in SLE, these genes are also expressed in other autoimmune diseases, such as rheumatoid arthritis.(3)

Furthermore, various drugs may also induce SLE known as drug induced SLE (DILE), among others isoniazid (INH), a tuberculosis (TB) antibiotic, that is metabolized by N-acetyltransferase2 (NAT2) enzyme. (4) This catalytic enzyme, encoded by NAT2 gene, has a pivotal role in detoxifies and inactivates some drugs for example hydrazine drugs, as well as xenobiotics, and also metabolizes carcinogenic arylamines and other chemicals in the liver.(5) Interestingly, INH, as one of the primary $\mathrm{TB}$ drugs, has been used as a model drug in silico to determine acetylation phenotype.(6)

The acetylation phenotype or acetylation rate varies from person to person.(7) Individual acetylation rate or acetylator status is classified into rapid, intermediate or slow acetylators, based on the co-dominant expression of NAT2 haplotypes.(8) NAT2 gene, located at chromosome 8p22, exhibits several variants, comprising NAT2 haplotype. The haplotype heterozygous NAT2 $* 4 / 6$ and homozygous NAT2 $* 5 / * 5$ has been reported to be more frequent in SLE patients, compared to control group of which the NAT2 $* 5 / * 6$ is more prevalent.(9) Interestingly, the slow acetylator individual may be prone to develop SLE later in life.(10)
Since the NAT2 haplotype varies among population, the aim of this study was to determine the distribution of NAT2 acetylator status which was explored among SLE patients with or without TB history from Bandung, Indonesia, as this country is a TB endemic area.(11)

\section{Methods}

\section{Design of The Study}

The design of this study was a descriptive cross-sectional study, exploring the NAT2 acetylator status among SLE patients living in a TB endemic area, therefore, history of TB in SLE patients was assessed.

\section{Recruitment of SLE Patients}

This study was part of a larger SLE patient registry at The Rheumatology Clinic of Dr. Hasan Sadikin General Hospital (Dr. Hasan Sadikin Lupus Regitry, (HSLR)). Consecutive clinical data of SLE patients registered during January 2016 to May 2018 were collected, including TB history and treatment. SLE patients were further grouped into SLE patients with or without history of TB. No exclusion criteria in this study. Systemic Lupus Erythematosus Disease Activity Index (SLEDAI) index and organ damage were assessed.(12) The study protocol was approved by the Ethical Research Committee of Medical Faculty, Universitas Padjadjaran No. 36/UN6.KEP/EC/2018.

\section{DNA Extraction and Amplification}

During a routine visit in the outpatients clinic, blood samples were collected into ethylenediaminetetraacetic acid (EDTA)-coated tubes. DNA was extracted and stored at $-20^{\circ} \mathrm{C}$ according to the manufacturer's instructions (Qiagen, Hilden, Germany). NAT2 gene was amplified in a final volume of $50 \mu \mathrm{L}$, containing of $1 \mathrm{U}$ polymerase chain reaction (PCR) MyTaq ${ }^{\mathrm{TM}}$ HS Master Mix (Bioline, London, UK), $20 \mu \mathrm{M}$ for each primer forward and reverse as published earlier (13), and 200ng DNA template. PCR was performed by PCR Thermal Cycler Eppendorf 5331 Mastercycler (Marshall Scientific, Hampton, USA) with PCR condition as followed: $95^{\circ} \mathrm{C}$ initiation phase for 3 min, followed by 35 cycles of denaturation at $95^{\circ} \mathrm{C}$ for 15 $\mathrm{s}$, annealing at $50^{\circ} \mathrm{C}$ for $15 \mathrm{~s}$, and elongation at $72^{\circ} \mathrm{C}$ for 60 $\mathrm{s}$, and ended by a cycle of final extension at $72^{\circ} \mathrm{C}$ for $5 \mathrm{~min}$. The PCR product was further sequenced for one direction of forward sequencing. NAT2 gene variants were then aligned and acetylator status was determined. 


\section{Molecular Analysis of NAT2 Variants and Acetylator Status Determination}

Sequence of NAT2 gene was analyzed using ClustalX for multiple alignments with sequence reference from GenBank (Acc. No. KR231610). Variants of NAT2 gene were assessed and the acetylator status of SLE patients was determined and classified into three groups, including slow, intermediate and fast acetylator based on NAT2 acetylator nomenclature (http://nat.mbg.duth.gr/Human\%20NAT2\%20alleles_2013. htm.). In brief, fast acetylation is coded by wild-type NAT2*4 alleles or NAT2*13, while impaired acetylation has various alleles i.e. intermediate (heterozygous) or slow (homozygous) acetylator status was determined according to nucleotide change in $341 \mathrm{~T}>\mathrm{C}$ (NAT2*5), $590 \mathrm{G}>\mathrm{A}$ (NAT2*6), $857 \mathrm{G}>\mathrm{A}(\mathrm{NAT2} * 7)$. When sequences were found not in nomenclature yet, they were designated as 'ND (cannot determined)'.

\section{Results}

During January 2016 to May 2018, 264 consecutive SLE patients, older than 16 years old were registered at The Rheumatology Outpatient Clinic of Dr. Hasan Sadikin General Hospital, Bandung, Indonesia. Only 260 DNA of these SLE patients were successfully sequenced for NAT2 haplotype and acetylator status was then determined. At the time of inclusion in the study, only 245 (94.2\%) SLE patients were still followed up, 9 were lost and 6 died due to infection, particularly caused by community acquired pneumonia.

SLE patients registered were predominantly female $(96.2 \% ; n=250)$ of whom $6 \%(n=20)$ were female $>50$ years old. The median age when SLE was diagnosed was 27 years old (range 8-69 years), and no statistical different ( $p=0.824$ ) between male and female patients as shown in Table 1. Interestingly, $4.2 \%(\mathrm{n}=11)$ of these SLE patients were diagnosed at young age of $<15$ years old, and 3.1\% $(n=8)$ were at older age of $>50$ years old. Most of the female SLE patients were non-smokers $(76.1 \% ; \mathrm{n}=198$ of 250$)$ in contrast to male SLE patients who were active or passive smokers $(60 \%, n=6$ of 10$)$. Of note, passive smokers were present in 49 of $250(19.6 \%)$ female SLE patients (Table 1). As for clinical involvement, the most affected organs were musculoskeletal (80.8\%) and mucocutaneous $(73.1 \%)$ as depicted in Table 2. Disease activity of lupus at the time of subjects recruited was measured with SLEDAI showed that most patients (71.6\%) had no disease activity. Up to $98.9 \%$ patients received methylprednisolone, while the other given drugs is described in Table 2.

Patients were grouped into SLE patients with no TB history ( $\mathrm{n}=200 ; 76.9 \%)$, SLE patients with TB history, consisting TB history before SLE diagnosis ( $\mathrm{n}=27 ; 10.4 \%$ ), after SLE diagnosis $(n=28 ; 10.7 \%)$ and in both periods of

Table 1. Clinical characteristics of SLE patients registered at Dr. Hasan Sadikin General Hospital, Bandung, Indonesia, during January 2016 to May 2018.

\begin{tabular}{|c|c|c|c|}
\hline Characteristics & $\begin{array}{c}\text { Male } \\
(n=10)\end{array}$ & $\begin{array}{l}\text { Female } \\
(n=250)\end{array}$ & $p$-value \\
\hline \multicolumn{4}{|l|}{ Age; years } \\
\hline Median (min-max) & $34.5(16-47)$ & $32(16-73)$ & 0.873 \\
\hline \multicolumn{4}{|l|}{ Age Group; n (\%) } \\
\hline$<50$ years & $10(3.8)$ & $230(88.4)$ & n.d \\
\hline$\geq 50$ years & - & $20(7.6)$ & \\
\hline \multicolumn{4}{|l|}{ Age at SLE diagnosis; years } \\
\hline Median (min-max) & $30.5(13-42)$ & $27(8-69)$ & 0.824 \\
\hline \multicolumn{4}{|c|}{ Age Group at SLE diagnosis; n (\%) } \\
\hline$<15$ years & $1(0.4)$ & $10(3.8)$ & n.d \\
\hline $15-50$ years & $9(3.5)$ & $232(89.2)$ & \\
\hline$>50$ years & - & $8(3.1)$ & \\
\hline \multicolumn{4}{|l|}{ Smoking; n (\%) } \\
\hline Non-smoker & $4(40)$ & $198(79.2)$ & n.d \\
\hline Active smoker & $3(30)$ & $3(1.2)$ & \\
\hline Passive smoker & $3(30)$ & $49(19.2)$ & \\
\hline
\end{tabular}

SLE: systemic lupus erythromatosus; n.d not determined. 
Table 2. Organ involvement, disease activity, SLE therapy and TB history during SLE period. among patients from Dr. Hasan Sadikin General Hospital, Bandung, Indonesia.

\begin{tabular}{|c|c|}
\hline Categories & n $(\%)$ \\
\hline \multicolumn{2}{|l|}{ Organ Involvement } \\
\hline Musculoskeletal & $210(80.8)$ \\
\hline Mucocutanous & $190(73.1)$ \\
\hline Nephritis & $118(45.4)$ \\
\hline Hematological & $86(33.1)$ \\
\hline Neuropsychiatric & $45(17.3)$ \\
\hline \multicolumn{2}{|l|}{ SLEDAI* } \\
\hline No Activity & $189(71.6)$ \\
\hline Mild & $66(25)$ \\
\hline Moderate & $8(3)$ \\
\hline Severe & $1(0.4)$ \\
\hline \multicolumn{2}{|l|}{ SLE Therapy } \\
\hline Methylprednisolone & $261(98.9)$ \\
\hline Azathioprine & $143(54.2)$ \\
\hline Chloroquine & $147(55.7)$ \\
\hline Cyclophosphamide & $48(18.2)$ \\
\hline Methotrexate & $10(3.8)$ \\
\hline Cyclosporine & $16(6.1)$ \\
\hline Mycophenolate mofetil & $14(5.3)$ \\
\hline \multicolumn{2}{|l|}{ TB history } \\
\hline No TB history & $200(76.9)$ \\
\hline TB history & $60(23.1)$ \\
\hline \multicolumn{2}{|l|}{ TB pre SLE } \\
\hline Pulmonary TB & $15(5.8)$ \\
\hline Extra Pulmonary & $12(4.6)$ \\
\hline \multicolumn{2}{|l|}{ TB post SLE } \\
\hline Pulmonary TB & $17(6.5)$ \\
\hline Extra Pulmonary & $11(4.2)$ \\
\hline TB pre \& post SLE & $5(2)$ \\
\hline
\end{tabular}

*SLEDAI: Systemic Lupus Erythematosus Disease Activity Index.

before and after SLE diagnosis $(\mathrm{n}=5 ; 2.0 \%)$ as shown in Table 2 with detailed pulmonary or extra pulmonary TB. All patients with TB history were asked for their TB treatment, and INH was noted as one of the drugs among TB regiment of all these patients.

\section{NAT2 Haplotype and Acetylator Status Among SLE Patients}

The sequences of NAT2 gene variants were analysed in this study. The most prevalent variant was G590A (55.4.\%), consisting of heterozyogous GA (45\%) and homozygous AA $(10.4 \%)$ as this variant was dominant in NAT2*6 haplotype, while others were C282T (30.4\%), T341C (16.9\%), C481T (10.8\%), A803G (16.9\%), G857A (21.5\%) (shown in Supplement 1). Analysis of the haplotype wild type NAT2*4 $(21.5 \%)$, haplotype NAT2*6B $(25.8 \%)$ and NAT2*6A $(12.7 \%)$ were the most prevalent haplotype in SLE patients from Bandung, Indonesia as shown in Table 3. The acetylator status among SLE patients from Bandung were detected in trimodale mode as fast acetylator (59 cases; $22.7 \%$ ) consisted of NAT2*4 wild type and NAT2*12A (homozygous or heterozygous), and as intermediate (160 cases; $61.5 \%$ ) and slow acetylator (37 cases; $14.3 \%$ ). We have found new variants in NAT2 gene in our samples (n4; $1.5 \%)$ that did not belong to known haplotype.

\section{NAT2 Acetylator Status and TB History Among SLE Patients}

There were 32 patients who had TB history before SLE was diagnosed of whom 27 had TB only before SLE diagnosis and 5 others had TB in both periods i.e., before and after SLE diagnosis as shown in Table 4. Most of the SLE patients recovered well from TB infection.

\section{Discussion}

The immunopathogenesis of SLE is complex and not fully understood yet.(14) Gene interaction to some drugs and/ or enzymes that metabolize certain drugs may play an important role. This is the first SLE study in Indonesia, exploring NAT2 haplotypes and acetylator status among SLE patients recruited from SLE registry in TB endemic area Bandung, Indonesia.

The distribution of NAT2 variants and haplotypes have been extensively studied in different ethnic groups. The most prevalent variant in our study is G590A (55.4\%), while study in Brazil is G857A.(15) The distribution of the most prevalent NAT2 haplotypes in our study are the wild type NAT2*4 (21.5\%), haplotype NAT2*6B (25.8\%) and NAT2*6A (12.7\%) (Table 3); and the acetylator status among SLE patients from Bandung fast acetylator (22.7\%), intermediate $(61.5 \%)$ and slow $(14.3 \%)$. Slow acetylator may have impacted the TB therapy with the development of drug induced liver injury (DILI) or hepatotoxicity, as confirmed by several studies across population.(16-18) Therefore, individual with slow acetylator status may have been exposed with TB drugs longer, especially INH, and prone to develop SLE.(19)

Study in Japan showed that environmental factor such as cigarette smoking has been associated with increased risk 
Table 3. Haplotype distribution among NAT2 acetylator status of SLE patients registered at Dr. Hasan Sadikin General Hospital, Bandung, Indonesia

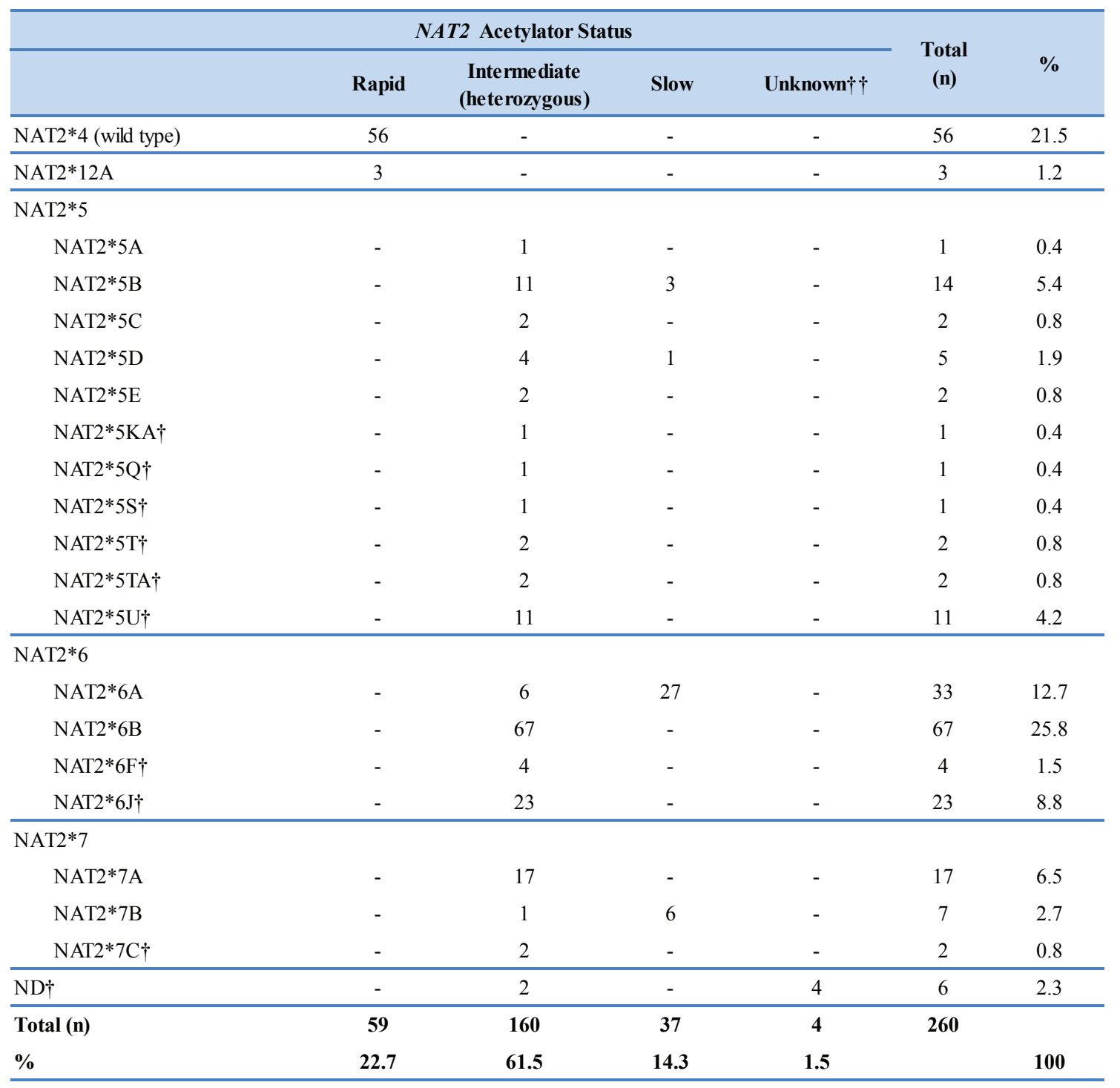

NAT2 haplotype according to http://nat.mbg.duth.gr/Human\%20NAT2\%20alleles_2013.htm. ND (cannot determined): haplotype not in nomenclature yet; $\uparrow$ : haplotype with unknown acetylator status, however, intermediate and slow acetylator status is determined according to nucleotide change in $341 \mathrm{~T}>\mathrm{C}$ (NAT2*5), $590 \mathrm{G}>\mathrm{A}$ (NAT2*6), $857 \mathrm{G}>\mathrm{A}$ $(\mathrm{NAT} 2 * 7) ; \dagger \dagger$ : unknown acetylator status.

to SLE, especially in individual with NAT2 slow acetylator genotype.(9) Tobacco, the ingredients of cigarette, is classified into aromatic amines that needs to be detoxified by $\mathrm{N}$-acetyltransferase enzyme. Passive smoker are prevalent among female SLE patients (19.2\%) where the household members especially male are smokers.

Furthermore, study results of NAT2 acetylator status in relation with SLE are conflicting. Eventhough slow acetylators are more prevalent in SLE patients compared to their healthy controls, 9 others studies showed lack of evidence for this asscociation. $(20,21)$ In our study, we are lacking of control group, therefore, the real association of slow acetylator status and susceptibility to SLE could not be further analyzed.

Although the result is contradicting, we have drawn special attention on TB history among SLE patients as Indonesia harbors $\mathrm{TB}$ patients being the second of TB prevalence globally, and thus the chance of getting Mycobacterium tuberculosis infection is high and latent TB infection may exist. Infection is known as one of the common trigger factors for SLE. Study showed that Mycobacterium tuberculosis infection may have a role in precipitating SLE through immunomodulatory action. $(22,23)$ In the other hand, SLE patient is vulnerable to 
Table 4. NAT2 acetylator status distribution in association with TB prevalence and TB therapy outcome among SLE patients with history of TB registered at Dr. Hasan Sadikin General Hospital, Bandung, Indonesia.

\begin{tabular}{|c|c|c|c|c|c|}
\hline & \multirow{2}{*}{$\begin{array}{c}\text { Total } \\
\text { N }\end{array}$} & \multicolumn{4}{|c|}{ NAT2 Aceytolator Status } \\
\hline & & $\begin{array}{l}\text { Rapid } \\
\text { N (\%) }\end{array}$ & $\begin{array}{l}\text { Intermediate } \\
\qquad \mathbf{N}(\%)\end{array}$ & $\begin{array}{c}\text { Slow } \\
\text { N (\%) }\end{array}$ & $\begin{array}{c}\text { Unknown } \dagger^{\dagger} \dagger \\
\text { N (\%) }\end{array}$ \\
\hline \multicolumn{6}{|l|}{ TB prevalence } \\
\hline SLE with no TB history & 200 & $43(21.5)$ & $129(64.5)$ & $29(14.5)$ & $4(2.0)$ \\
\hline \multicolumn{6}{|l|}{ SLE with TB history } \\
\hline before SLE diagnosis & 27 & $8(29.6)$ & $15(55.6)$ & $4(14.8)$ & - \\
\hline after SLE diagnosis & 28 & $6(21.4)$ & $18(64.3)$ & $4(14.3)$ & - \\
\hline before \& after SLE diagnosis & 5 & $2(40.0)$ & $3(60.0)$ & - & - \\
\hline \multicolumn{6}{|l|}{ TB therapy outcome } \\
\hline before SLE diagnosis* & 32 & & & & \\
\hline Recovered & 26 & $7(21.9)$ & $15(46.9)$ & $4(12.5)$ & \\
\hline Relapse & 5 & $2(15.6)$ & $3(9.4)$ & - & \\
\hline Failed & 1 & $1(3.1)$ & - & - & \\
\hline after SLE diagnosis** & 33 & & & & \\
\hline Recovered & 26 & $6(18.2)$ & $16(48.5)$ & $4(12.1)$ & \\
\hline Relapse & 5 & $2(6.1)$ & $3(9.1)$ & - & \\
\hline Failed & 1 & - & $1(3.0)$ & - & \\
\hline Died & 1 & - & $1(3.0)$ & - & \\
\hline
\end{tabular}

SLE: Systematic Lupus erythematosus; TB: tuberculosis; n.d: not determined. * SLE patients with TB before SLE and with TB before \& after SLE diagnosis together. ** SLE patients with TB after SLE and with TB before \& after SLE diagnosis together. $\uparrow \uparrow:$ unknown acetylator status, however, intermediate and slow acetylator status is determined according to nucleotide change in $341 \mathrm{~T}>\mathrm{C}$ (NAT2*5), $590 \mathrm{G}>\mathrm{A}$ (NAT2*6), $857 \mathrm{G}>\mathrm{A}$ (NAT2*7).

infection due to dysregulation of multiple aspects in the immune system.(24) Interestingly, some antibiotics against infections in particular may also predispose the SLE development, known as DILE.(19)

Mycobacterium tuberculosis infection may develop after SLE. This infection is possible due to various immunosuppressive or corticosteroid agent needed for SLE therapy, either infection from the neighboring people or latent TB infection re-activation. An extra pulmonal tuberculosis infection is common (25) although in our study extra pulmonal TB has an equal percentage compared to pulmonary TB. When TB infection after SLE is diagnosed, the NAT2 acetylator status determination may have beneficial of clinical importance, not only for SLE chemotherapy but also for TB therapy. Further studies on pharmacokinetic, -dynamics and-genetic in SLE drugs may have a great interest.(26)

\section{The Limitation of The Study}

This NAT2 acetylator status study does not compare SLE patients as cases $v s$. healthy individuals as controls, therefore, this study is limited and can not explore the analysis regarding the role of NAT2 acetylator status and SLE susceptibility. As for TB history, no laboratory data on liver function, thus, drug induced liver injury can not be assessed. An integrative SLE and TB collaborative care need to be implemented.

\section{Conclusion}

The distribution of intermediate and slow NAT2 acetylator status among SLE patients from Bandung, Indonesia is predominant as high as $65.4 \%$ and $11.9 \%$, respectively. In the area where TB prevalence is high, acetylator status determination among SLE patients may have an important role before INH therapy to guide for successful TB treatment.

\section{Acknowledgements}

We are greatly thankful to SLE patients who participated in this study. We appreciate Rachmat Gunadi Wachjudi, Sumartini Dewi, Andri Reza Rahmadi, for their great 
collaboration in SLE registry. This study was supported by Prodia Education and Research Institute (PERI) Grant Year 2018.

\section{References}

1. Choi J, Kim ST, Craft J. The pathogenesis of systemic lupus erythematosus-an update. Curr Opin Immunol. 2012; 24: 651-7.

2. Kaul A, Gordon C, Crow MK, Touma Z, Urowitz MB, van Vollenhoven R, et al. Systemic lupus erythematosus. Nat Rev Dis Primers. 2016; 2:16039. doi: 10.1038/nrdp.2016.39.

3. Harley IT, Kaufman KM, Langefeld CD, Harley JB, Kelly JA. Genetic susceptibility to SLE: new insights from fine mapping and genome-wide association studies. Nat Rev Genet. 2009; 10: 285-90.

4. Antonov D, Kazandjieva J, Etugov D, Gospodinov D, Tsankov N. Drug-induced lupus erythematosus. Clin Dermatol. 2004; 22: 15766.

5. Rajasekaran M, Abirami S, Chen C. Effects of single nucleotide polymorphisms on human $\mathrm{N}$-acetyltransferase 2 structureand dynamics by molecular dynamics simulation. PLoS ONE. 2011; 6: e25801. doi: 10.1371/journal.pone.0025801.

6. Unissa AN, Sukumar S, Hanna LE. The role of N-acetyltransferases on isoniazid resistance from mycobacterium tuberculosis and human: an in silico approach. Tuberc Respir Dis. 2017; 80: 255-64.

7. Sabbagh A, Darlu P, Crouau-Roy B, Poloni ES. ArylamineNacetyltransferase 2 (NAT2) genetic diversity and traditional subsistence: a worldwide population survey. PLoS ONE.2011; 6: e18507. doi: 10.1371/journal.pone.0018507.

8. Hein DW, Doll MA. Accuracy of various human NAT2 SNP genotyping panels to infer rapid, intermediate and slow acetylator phenotypes. Pharmacogenomics. 2012; 13: 31-41.

9. Kiyohara C, Washio M, Horiuchi T, Tada Y, Asami T, Ide S, et al. Cigarette smoking, $\mathrm{N}$-acetyltransferase 2 polymorphisms and systemic lupus erythematosus in a Japanese population. Lupus. 2009; 18: 630-8.

10. Cooper GS, Treadwell EL, Dooley MA, St Clair EW, Gilkeson GS, Taylor JA. N-acetyl transferase genotypes in relation to risk of developing systemic lupus erythematosus. J Rheumatol. 2004; 31 : 76-80.

11. World Health Organization. Global Tuberculosis Report 2017. WHO Report 2017. Geneva: WHO; 2017.

12. Anić F, Zuvić-Butorac M, Stimac D, Novak S. New classification criteria for systemic lupus erythematosus correlate with disease activity. Croat Med J. 2014; 55: 514-9.

13. Sahiratmadja E, Penggoam S, Maskoen AM, Pramono AA, Aryani D, Rahayu NS, et al. Distribution of rs1801279 and rs1799930 polymorphisms in NAT2 gene among population in Kupang, Nusa Tenggara Timur, Indonesia. Indones Biomed J. 2018; 10: 56-61.

14. Tsokos GC, Lo MS, Costa Reis P, Sullivan KE. New insights into the immunopathogenesis of systemic lupus erythematosus. Nat Rev Rheumatol. 2016; 12: 716-30.

15. dos Santos EC, Pinto AC, Klumb EM, Macedo JM. Polymorphisms in NAT2 (N-acetyltransferase 2) gene in patients with systemic lupus erythematosus. Rev Bras Reumatol Engl Ed. 2016; 56: 521-9.

16. Wattanapokayakit $\mathrm{S}$, Mushiroda $\mathrm{T}$, Yanai $\mathrm{H}$, Wichukchinda $\mathrm{N}$, Chuchottawon C, Nedsuwan S, et al. NAT2 slow acetylator associated with anti-tuberculosis drug-induced liver injury in Thai patients. Int J Tuberc Lung Dis. 2016; 20: 1364-9.

17. Zabost A, Brzezińska S, Kozińska M, Błachnio M, Jagodziński J, Zwolska Z, et al. Correlation of $\mathrm{N}$-acetyltransferase 2 genotype with isoniazid acetylation in Polish tuberculosis patients. Biomed Res Int. 2013; 2013: 853602. doi: 10.1155/2013/853602.

18. Yuliwulandari R, Susilowati RW, Wicaksono BD, Viyati K, Prayuni $\mathrm{K}$, Razari I, et al. NAT2 variants are associated with drug-induced liver injury caused by anti-tuberculosis drugs in Indonesian patients with tuberculosis. J Hum Genet. 2016; 61: 533-7.

19. Chang C, Gershwin ME. Drug-induced lupus erythematosus: incidence, management and prevention. Drug Saf. 2011; 34: 357-74.

20. Zschieschang P, Hiepe F, Gromnica-Ihle E, Roots I, Cascorbi I. Lack of association between arylamine $\mathrm{N}$-acetyltransferase 2 (NAT2) polymorphism and systemic lupus erythematosus. Pharmacogenetics. 2002; 12: 559-63.

21. Rychlik-Sych M, Skretkowicz J, Gawrońska-Szklarz B, Górnik W, Sysa-Jedrzejowska A, Skretkowicz-Szarmach K. Acetylation genotype and phenotype in patients with systemic lupus erythematosus. Pharmacol Rep. 2006; 58: 22-9.

22. Ghosh K, Patwardhan M, Pradhan V. Mycobacterium tuberculosis infection precipitates SLE in patients from endemic areas. Rheumatol Int. 2009; 29: 1047-50.

23. Jung JY, Suh CH. Infection in systemic lupus erythematosus, similarities, and differences with lupus flare. Korean J Intern Med. 2017; 32: 429-38.

24. Lin YC, Liang SJ, Liu YH, Hsu WH, Shih CM, Sung FC, et al. Tuberculosis as a risk factor for systemic lupus erythematosus: results of a nation wide study in Taiwan. Rheumatol Int. 2012; 32: 1669-73.

25. Tam LS, Li EK, Wong SM, Szeto CC. Risk factors and clinical features for tuberculosis among patients with systemic lupus erythematosus in Hong Kong. Scand J Rheumatol. 2002; 31: 296-300.

26. Azuma J, Ohno M, Kubota R, Yokota S, Nagai T, Tsuyuguchi K, et al. NAT2 genotype guided regimen reduces isoniazid-induced liver injury and early treatment failure in the 6-month four-drug standard treatment of tuberculosis: a randomized controlled trial for pharmacogenetics-based therapy. Eur J Clin Pharmacol. 2013; 69: 1091-101. 